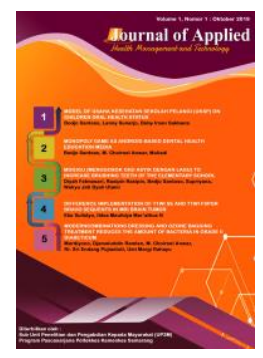

\title{
Journal of Applied Health Management and Technology
}

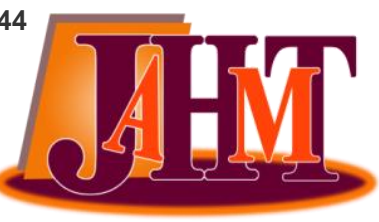

p-ISSN: 2715-3061

e-ISSN: 2715-307X

\section{DEVELOPMENT OF TOOLS OF THE X-RAY COLLIMATOR (DEV-X)}

\author{
I Made Lana Prasetya $^{1}$, Hari Santoso ${ }^{2}$, Gatot Murti Wibowo ${ }^{3}$ \\ ${ }^{I}$ Port Health Office of Denpasar Bali, Indonesia \\ ${ }^{2}$ Postgraduate Program Poltekkes Kemenkes Semarang, Indonesia \\ ${ }^{3}$ Postgraduate Program Poltekkes Kemenkes Semarang, Indonesia \\ Corresponding author: I Made Lana Prasetya \\ Email: lanaprasetya182@gmail.com
}

\begin{abstract}
Technological developments, especially in the field of radiology, is growing rapidly. The radiology quality assurance system has also developed, one of which is the Collimator Test Tools. The method of testing $\mathrm{x}$-ray beams using this tool has also been developed, such as using film and using IP. However, the development of this method has a drawback, namely that the examiner is required to have special skills in image post-processing. The development of Collimator Test Tools by utilizing the nature of x-rays which causes certain substances such as calcium tungstate or zinc sulfide to glow light (luminance) has been done a lot, but there is no study of these products. Therefore, the researcher wants to develop a product by designing a Collimator test tool based on digital image analysis technology (Dev$\mathrm{X}$ ) and a digital camera with Android-based calculations on a wirelessly connected smartphone as an update of the testing method. Objective: To create a collimator test tool for $\mathrm{x}$-ray machines based on digital image analysis technology (Dev-X). This is a research experiment with a posttest group only design type. Research Location at the Radiology Laboratory of the Radiodiagnostic and Radiotherapy Engineering Academy (ATRO) Bali. Functional Test of Dev-X Products (hardware and software), all components function properly. However, it cannot be assessed significantly from statistical results. Conclusion: The creation and proper functioning of hardware and software tools collimator test tool DevXon android smartphone and show the calculation results of the x-ray beam automatically.
\end{abstract}

Keywords: Quality Control, Collimator Test Tools, Digital Image Processing

\section{Introduction}

Technical efforts to detect early and prevent conditions of mismatch in the function of the collimator components, a testing and monitoring program is needed or known as theProgram Quality Control (QC) X-ray at health facilities in the Radiodiagnostic section. The radiodiagnostic $\mathrm{x}$-ray equipment $\mathrm{QC}$ program is part of the Quality Assurance (QA) Program, which is in the form of activities to measure the performance of significant components of $\mathrm{x}$-ray equipment quantitatively and continuously so that it can be seen the condition of the equipment's feasibility to be used in radiographic examinations for patients. ${ }^{1}$

Testing to determine the performance of this collimator can be done using various methods, including the collimator test tool designed to evaluate collimator performance (Collimator test tools). Physical parameters evaluate the collimator's performance by measuring and calculating the percentage 
suitability of the coordinates on the abscissa (X) and ordinate $(\mathrm{Y})$, including the percentage of the difference $(\Delta)$. The area of the X-ray field must be congruent with the collimator's light field on the abscissa and ordinate sides. The tolerance stated that it is still appropriate/appropriate is if the percentage of $\mathrm{X}$ and $\mathrm{Y}$ shift $\leq 2 \%$ (maximum) of the focus distance to the film plane / Focus Film Distance (FFD) and the percentages $\Delta \mathrm{X}$ and $\Delta \mathrm{Y} \leq 3 \%$ of the focal distance to the film plane / Focus Film Distance $(\text { FFD })^{2}$

Collimator test tools have been widely circulating in the market as testing tools and methods. The Directorate of Engineering and Nuclear Preparedness of BAPETEN issued a product in the form of a sheet of paper with a rectangular image measuring $18 \mathrm{~cm} \mathrm{x} 14 \mathrm{~cm}$ in its use, using 8500 rupiah coins or 1000 rupiah coins which were used as x-ray markers exposed to the receptor image and file calculations. collimations still use manual calculations. Some examples of other testing tools and methods are the RMI Collimator Test Tools and the Gammex $161 \mathrm{~B}^{3}$

Collimator Test Tools. Made of brass, centimeter strokes on its surface can give direct dimensions to a radiograph with normal $\mathrm{x}$-ray exposure. With this test method, the measurement of the field area of the x-ray beam and collimator light still requires $\mathrm{x}$-ray tapes and film or can also be used on the Imaging Plate (IP) Computer Radiography (CR) or Digital Radiography (DR), where calculations are done still manually with mathematical equations. From an economic point of view, this product is priced at approximately Rp. 9,000,000; depending on foreign currency exchange rates, because this tool is imported from abroad. ${ }^{4}$

Testing and measuring collimator performance without using X-ray film (filmless), namely using an image plate (imaging plate). The measured image (soft file) is evaluated and analyzed with the help of computer-based application post-processing-, on a Computer Radiography (CR) system as an alternative tool without film to assess the suitability of collimators and x-ray beams. However, special expertise in image processing is needed in analyzing using this method. ${ }^{5}$ As for a more modern, automatic tool with digital technology currently being developed, namely using a digital camera, one of which is a Nova RTI product. The technology used is a webcam with a cable of 10 meters with a maximum recommendation of SSD (Source To Skin Distance) at $75 \mathrm{~cm}$ and the calculation of the area of the field using a computer programmingbased application and the main component as an $\mathrm{x}$-ray beam marker, namely using a phosphorus ruler. The working principle of this tool is a webcam as image capture phosphor ruler before and after exposure to radiation so that the deviation can be measured between the collimated light beam and the x-ray beam shining on the phosphor ruler. The image captured by the webcam is opened in software special that is used as a calculation formulation for the deviation of the $\mathrm{x}$-ray beam and collimated light. This product is priced at approximately Rp. 35,000,000; in the sales package $^{6}$

In the Radiology Laboratory of the Academy of Radiodiagnostic and Radiotherapy (ATRO) Bali, a general radiograph machine have been installed stationary. The radiographic machine with the MIS brand model MCR-901R with a maximum rating of $150 \mathrm{kVp}$ was subjected to routine calibration once the last 4 years on 23 February 2017 and quality control was guaranteed once a year using collimator test tools Leeds Test Objects Phantom type TOR $\mathrm{ABC}$ made of acrylic blend with a brass grid as a deviation marker with the film screen testing procedure so that the calculation still uses mathematical equations.

According to the Decree of the Minister of Health of the Republic of Indonesia No. 1014 of 2008 concerning Radiology Service Standards, the quality control system is done at least once a year (Decree of the Minister of Health of the Republic of Indonesia, 2008) and according to the Decree of the Minister of Health of the Republic of Indonesia No 1250 of 2009 concerning Quality Control Guidelines (Quality Control) Radiodiagnostic equipment that the frequency of the collimator beam similarity test should be done once a month or after repair or maintenance of the tube and collimator housing. The frequency of testing can be multiplied depending on the size of the burden on the use of the machine. ${ }^{2}$ 
Therefore, researchers want to develop a product but with a simpler and more practical concept without reducing the quality of measurement and the accuracy of measuring $\mathrm{x}$ ray beams at a cost. affordability to achieve a quality control program at an institution that utilizes an $\mathrm{x}$-ray machine.

Technological developments, especially in radiology, are growing rapidly. The radiology quality assurance system has also developed, one of which is the Collimator Test Tools. The method of testing x-ray beams using this tool has also been developed, such as using film and using IP. However, the development of this method has a drawback, namely that the examiner is required to have special skills in image post-processing. The development of Collimator Test Tools by utilizing the nature of $\mathrm{x}$-rays which causes

certain substances such as calcium tungstate or zinc sulfide to glow light (luminance) has been done a lot, but there is no study of these products. Therefore, the researcher wants to develop a product by designing a Collimator test tool based on digital image analysis technology (Dev-X) and a digital camera with Android-based calculations on a smartphone a wirelessly connected an update of the testing method.

\section{Methods}

This type of research is experimental design true experimental by developing an existing method by designing and testing the function of the collimator test tool based on digital image analysis technology (Dev-X), with the type of posttest group only design. Research Location at the Radiology Laboratory of the Radiodiagnostic and Radiotherapy Engineering Academy (ATRO) Bali.

\section{Results \\ Preliminary Study Stages}

At the preliminary study stage, a literature study is carried out. The literature study material is theoretical material obtained from textbooks, journals, and articles. At this stage, observations of the research location were also carried out in the radiology laboratory of ATRO BALI, to determine the test equipment used in the laboratory and to analyze the development needs to be carried out.

\section{Hardware Dev-X}

1. Stages of Model Development

At this stage it is divided into three stages, namely:

a. Design Hardware.

1) Designing a laminate sticker in the form of a measurement scale pattern image and which will be attached to the acrylic and the intensifying screen.

2) Determine the thickness of the acrylic

3) Determine the digital camera that will be used.

4) Determine the thickness of the black sponge foam to be used.

5) Determine the distance to the camera height using a tripod.

6) Determine the tripod that will be used

b. The materials that will be used include:

1) Intensifying screen.

2) Clear acrylic

3) Transparent sticker.

4) Black foam.

5) Double tape.

6) Digital camera

7) Tripod

c. Dev-X Hardware Assembly.

1) Attaching black foam to the bottom side of the acrylic

2) Attaching the intensifying screen to the top and bottom acrylic of the acrylic

3) Attaching a transparent sticker that has been designed on the intensifying screen.

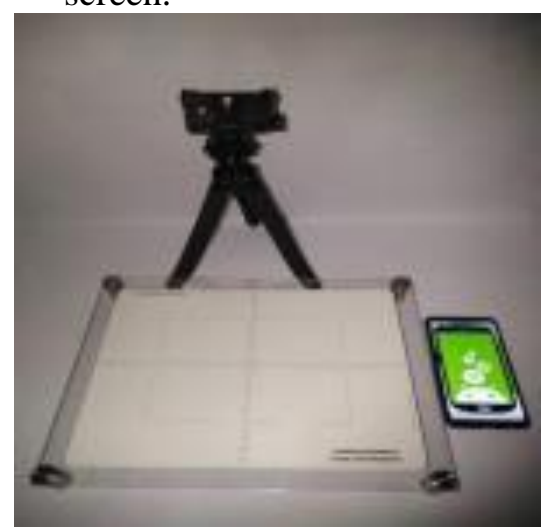

Figure 1. The prototype of the Dev-X Hardware Model

1. Stages of Testing the Dev-X (Hardware) 


\section{Model Function}

To determine the performance of the tool, it is necessary to do a test. This test is carried out as a benchmark, whether the tool is made to work as expected. The test was carried out at the ATRO Bali radiology laboratory. The Dev-X plate is placed perpendicular to the X-ray tube, set the FFD as high as $100 \mathrm{~cm}$ then the collimation opening is adjusted according to the mark on the Dev-X plate. $45 \mathrm{kV}$ and $\mathrm{mA}$ of 100 were used and the irradiation time was $1 \mathrm{~s}$. The action camera placed parallel with the Y2axis flexible tripod set up the camera angle range of $30^{\circ}-50^{0}$ to cover the entire plate Dev-X. The operator is behind the lead screen with a distance of approximately $2.5 \mathrm{~m}$.

2. Stages of the Dev-X (Hardware) Model Function Test Results.

From these tests, the results on the Dev$\mathrm{X}$ plate functioned well as expected by the researchers, the phosphorus light glow from the intensifying screen when exposed to radiation can be recorded properly by the action camera, but to produce maximum luminescence the researchers conducted several trials to ensure conditions. optimal exposure factor. In principle, the exposure factors used are $0-45 \mathrm{Kv}, 100-125 \mathrm{~mA}$ with 0.8-2second irradiation time.

3. Model Validation and Revision

Stages The model validation stage is the final stage of this research, which at this stage will produce a final model. In this stage, there are several steps, including the following:

a) Expert

validation Expert validation is carried out so that the hardware that is designed can be assessed for its feasibility based on expert judgment. The research instrument used was a validation sheet. Dev-X validation was carried out by 1 (one) expert, namely Anak Agung Aris Diarthama, S.ST, M. Tr. ID. Experts are experts with radiograph qualifications at ATRO BALI.

b) Final Revision

At this stage after Dev-X (Hardware) is validated, then a final revision is carried out according to the advice of the expert. In the expert validation step, it is carried out so that the designed Dev-X can find out its feasibility based on expert judgment. Advice from experts is in the form of input, namely:

In hardware "the use of acrylic on both sides has a risk of bias when reading the results". "TheÁlas from the Dev-X plate is better to use soft-touch material so that it provides when placed on the examination table" anti-slip has been refined and adjusted according to the validator's suggestion with the results "suggested revision results have been implemented properly".

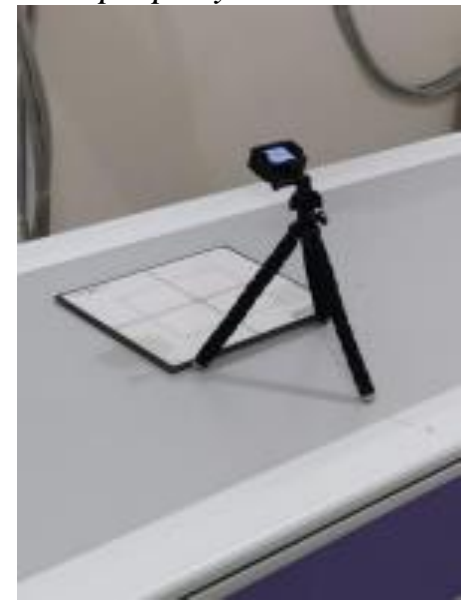

Figure 2. Final Model Hardware Dev-X

\section{Software Dev-X}

1. Model Development Stages

a. Design Software

Software is developed using android studio software. The design of the software through the following stages:

1) Designing the layout of the display on the smartphone

2) Determining the sequence of digital image processing that will be used

3) Designing the x-ray deviation calculation formulation

4) Coding software on the Android Studio.

5) Doing software rendering

6) Installing software on a smartphone

7) Doing software testing.

b. Software Dev-X.

The Dev-X software is developed through the Android Studio computer software which contains image processing and calculation of $\mathrm{x}$-ray files. The process 
before entering a video file into a smartphone, the user must download the video recording from the action camera to the smartphone via wifi connectivity.

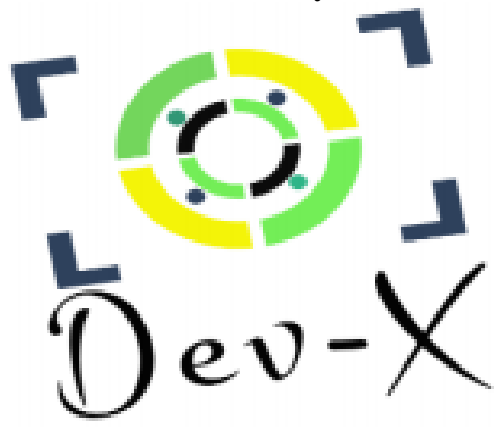

Figure 3. Icon Dev-X

1) Video to Image Grabbing.

A technique to take the desired image in video data. The image obtained is the most informative selected image in the video.

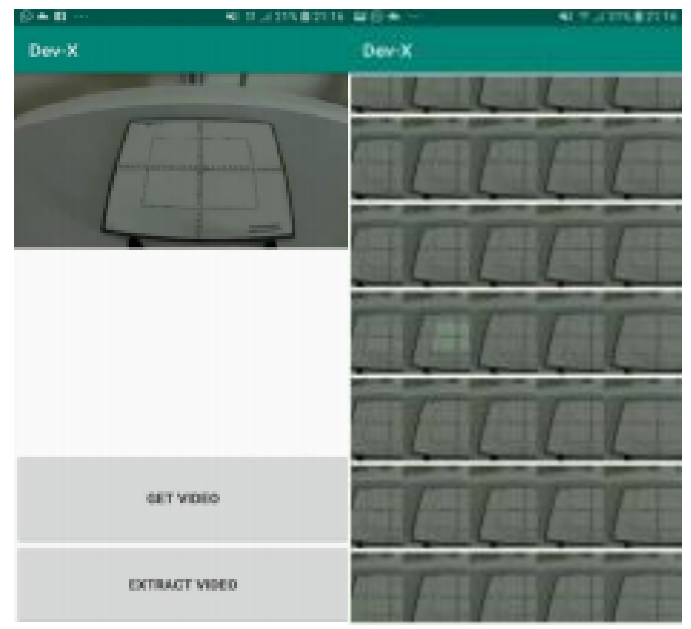

Figure 4. ScreenShoot Video to Image Grabbing Dev-X

2) Image Transformation.

This technique is a 2-dimensional digital image processing technique using mathematical methods with the concept of a side view into a viewpoint from above.

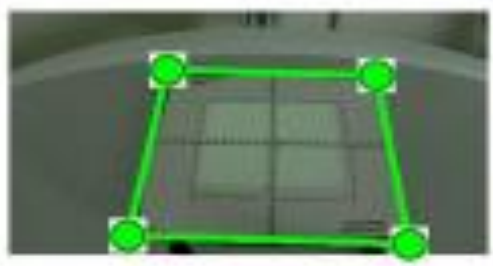

Figure 5. ScreenShoot Image
Transformation

3) system X-ray beam deviation calculation.

Contains a mathematical formula for calculating the $\mathrm{x}$-ray beam deviation. The collimation field deviation test formula with radiation field is $\mathrm{X} 1+$ $\mathrm{X} 2 \leq 2 \%$ of FFD and $\mathrm{Y} 1+\mathrm{Y} 2 \leq 2 \%$ of FFD or $\Delta \mathrm{X}+\Delta \mathrm{Y} \leq 3 \%$.

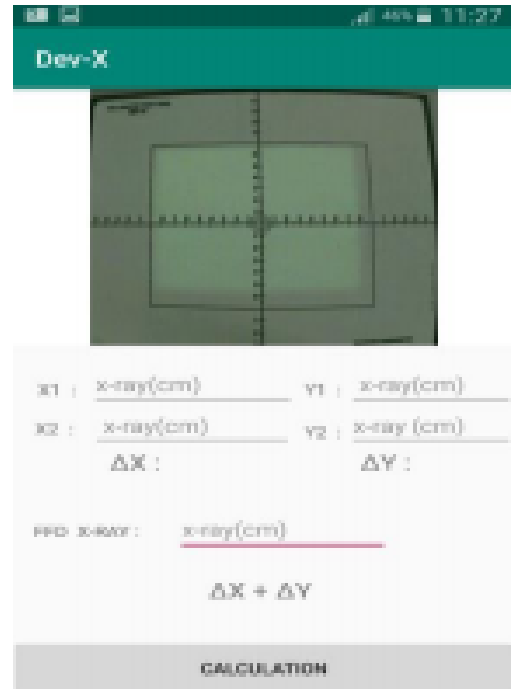

Figure 6. ScreenShoot of Android-Based Deviation Calculation System.

2. Stages of Testing the Dev-X (Software) Model Functions.

To find out the performance of the tool, it is necessary to do a test. This test is carried out as a benchmark, whether the tool is made to work as expected. The test was carried out at the ATRO Bali radiology laboratory. The Dev-X software is installed on the Samsung A5 2013 smartphone with the Android version 6.0.1 (Marshmallow).

3. Stages of the Dev-X (Software) Model Function Test Results.

The Dev-X software functions as data processing and calculation of $\mathrm{X}$-ray deviation, first the video that has been taken from the camera source through the default application of the action camera is then inputted in the Dev-X software then extracted into an image according to the number of image frames contained in the entire duration of the video, 
then the user selects an informative image as test data, after the image determined by the researcher inserts an image processing technique to clarify the reading of the results with a technique transformation perspective, then at the calculation stage by evaluating the image and inputting the data according to the specified column. The results that come out are Fail or Pass, fail means the collimator tested exceeds the recommended standard deviation, a pass means the collimator tested is in a state of normal limits.

4. Stages Model Validation and Revision

The model validation stage is the final stage of this research, which at this stage will result in the final model. In this stage, there are several steps, including the following:

a) Expert

validation Expert validation is carried out so that the hardware and software that is designed can be identified as feasible based on expert judgment. The research instrument used was a validation sheet. Expert validation of Android Dev-X software was chosen by a lecturer from STIMIK Primakara 1 (one) expert on biomedical engineering, machine learning, and image processing, namely I Putu Satwika, S. Kom., M. Kom.

b) Final Revision

At this stage after Dev-X (Software) is validated, then a final revision is carried out according to the advice of the expert. In the expert validation step, it is carried out so that the designed Dev- $X$ can find out its feasibility based on expert judgment. Advice from experts is in the form of input, namely: In the software, namely "Split video with a timeframe that is too small causing the application to experience a force close". "The image perspective transformation has a small size, needs to be enlarged to facilitate object recognition" has been adjusted to the validation results according to "validated that the revision given has been corrected and the application is running well".

\section{FieldField}

Testing trials were carried out in the radiology laboratory of ATRO Bali on an X-ray machine brand Medical Instrument System (Toshiba) Type E7239 with serial number $6 \mathrm{H} 0878$, max conditions $125 \mathrm{kV}$ and $300 \mathrm{~mA}$. Collimator model MCM-901R, SER.No1611042 with the specification of permanent filtration $1.1 \mathrm{~mm}$ Al.Eq. Field trials in this study are divided into 2, namely product functional tests and product performance tests.

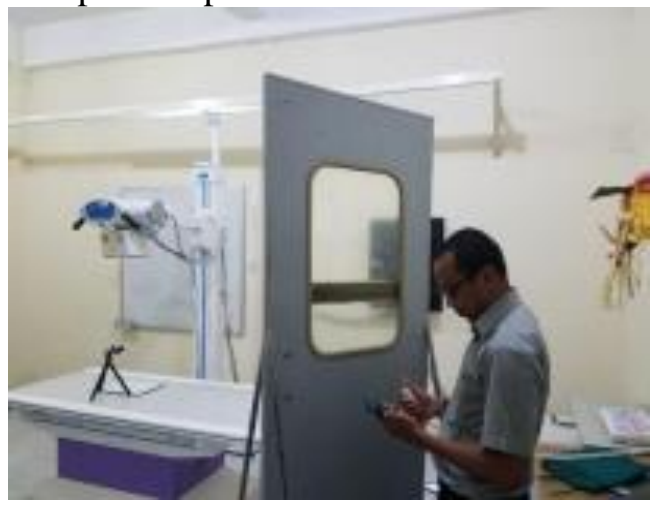

Figure 7. Dev-X Testing.

The product functional test aims to assess the work capability of the component system of the Dev-X product which is carried out by qualified experts, including the functions of the Dev-X plate component system, Action camera, and Dev-X Software developed based on Android OS on smartphones. The results of the function test of this component system areas in table 1 of the Dev-X Product Functional Test.

Table 1 Dev-X Product Functional Test.

\begin{tabular}{llll}
\hline \multirow{2}{*}{ Tool } & \multicolumn{2}{l}{ Function } & \multirow{2}{*}{ Description } \\
\cline { 2 - 3 } & Yes No & \\
\hline Plat Dev-X & $\sqrt{ }$ & Glows phosphor \\
& & light & \\
\hline Camera & $\sqrt{ }$ & Capable & of \\
& & Capturing the \\
& & glow of the & intensifying \\
& & screen. & \\
\hline Software & $\sqrt{ }$ & Function well. \\
\hline
\end{tabular}

In table 1. Functional Test of Dev-X Products, it can be seen that all components are functioning properly and can function as expected. On the Dev-X plate, the intensifying screen component can emit phosphor light. The camera can capture images when the intensifying screen shines phosphor light and 
can evaluate the image through a measurement scale attached to a clear sticker on the surface of the intensifying screen. And the digital image processing technique software embedded in the software (image grabbing, image transformation, and mathematical formulas for calculating x-ray deviation) can function properly.

Meanwhile, the product performance test aims to measure the performance of the product in producing the measured value of the collimator performance measurement parameters $(\mathrm{X}, \mathrm{Y} ; \Delta \mathrm{X}, \Delta \mathrm{Y}$, and $\Delta \mathrm{X}+\Delta \mathrm{Y})$.

The results of observations from measurements using the two methods are as described in tables 2 and 3, and for the next, the value of the Dev-X collimator suitability parameter is compared with the value of the TOR ABC gold standard measuring instrument (gold standard), as in tables 2, 3 and 4 .

Table 2. The test results of the $\mathrm{x}$-ray beam measurement for the collimator model MCM-901R, SER.No1611042 using the Dev-x test tool in centimeters.

\begin{tabular}{|c|c|c|c|c|c|c|c|}
\hline \multirow{3}{*}{$\mathrm{n}$} & \multicolumn{7}{|c|}{ Dev-X Collimator Test Tool $(\mathrm{cm})$} \\
\hline & $\mathrm{X} 1$ & $\mathrm{X} 2$ & $\Delta \mathrm{X}$ & Y1 & Y2 & $\Delta \mathrm{Y}$ & $\Delta X+\Delta$ \\
\hline & $\mathrm{dev}$ & $\mathrm{dev}$ & $\mathrm{dev}$ & $\mathrm{dev}$ & $\mathrm{dev}$ & $\mathrm{dev}$ & $Y_{\mathrm{dev}}$ \\
\hline 1 & 9 & 8 & 1 & 7 & 5.7 & 1.3 & 2.3 \\
\hline 2 & 9 & 8 & 1 & 7 & 5.7 & 1.3 & 2.3 \\
\hline 3 & 9 & 8 & 1 & 7 & 5.7 & 1.3 & 2.3 \\
\hline $\bar{\chi}$ & 0 & 1 & 1 & 0 & 1.3 & 1.3 & 2.3 \\
\hline$S$ & 2 & 2 & $\leq$ & 2 & 2 & $\leq$ & \\
\hline $\mathrm{D}$ & & & $2 \%$ & & & $2 \%$ & $\begin{array}{l}3 \\
\%\end{array}$ \\
\hline
\end{tabular}

In table 2 it can be seen that the results of the x-ray beam measurements carried out are the difference in the x-ray beam with a total deviation of $\Delta \mathrm{Xdev} \leq 2 \% \mathrm{FFD}$, namely $1 \mathrm{~cm}$ and on the sumbuYdev $\leq 2 \%$ FFD axis of $1.3 \mathrm{~cm}$, which means that the $\mathrm{x}$-ray plane collimator in radiology laboratory ATRO Bali uses Dev-X within normal limits, seen from the image on the X2dev and Y2dev axes, it is necessary to recalibrate to minimize the deviation on these axes.

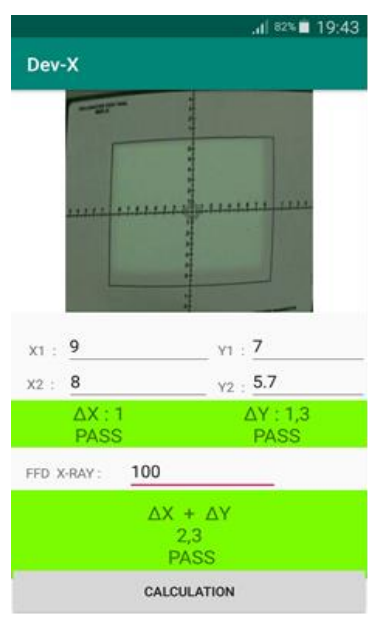

Figure 8 is a screenshot taken from a smartphone screen based on the Android OS on the Dev-X software.

\section{Discussion}

1. Stages of Preliminary Study

The advantage of Dev-X is that it is a tool developed from the principle of an intensifying screen that can emit phosphorus light. The researchers used the phosphorus light as an $\mathrm{x}$-ray beam marker and as a film substitute in analog image-based testing. Dev-X is said to be a collimator test tool based on digital image technology analysis because the phosphorus light that is driving is recorded by the action camera. The results of the video recordings are processed using Dev-X software so that the output of the test is a digital image and measurement data of the difference in $\mathrm{x}$-ray beams. The X-ray beam testing system in the Dev-X software suggests semi-automatic testing, users no longer need to calculate using mathematical formulas like testing using analog images. Another advantage of Dev- $\mathrm{X}$ is that it is more practical and simple to use but does not reduce the quality of the test and the accuracy of the test results.

2. Model Development Stage

Dev-X consists of hardware and software, Dev-X hardware is made of acrylic material as an intensifying screen adhesive medium coated with a transparent sticker as a 
scale marking $\mathrm{x}$-ray beam, then the base of Dev-X is in the form of black foam as an anti-slip. Acrylic is used with a thickness of $4 \mathrm{~mm}$ which aims to make the intensifying screen a glue and produce a stiff impression. Because the acrylic is slippery so it needs to be given black foam as an anti-slip when placed. The action camera is used because it has $4 \mathrm{k}$ video recording quality at $60 \mathrm{fps}$, so the hope is that it will be able to capture phosphorus luminescence images on the intensifying screen. Action camera used with the brand and type B-Pro 5 ES Mark IIs. The weakness of this hardware is that the resistance level of each material used has not been tested. The weakness of the Dev-X plate is that the use of automatic exposure control cannot maximize phosphorus glow. In terms of capturing images, the action camera is good at capturing these images.

Dev-X software was developed using an android studio. This software has the function of image processing and $\mathrm{x}$-ray data processing to be measured, where generally the conventional collimator testing uses physical film and mathematical equations to measure the difference in x-ray beams, so hopefully with this software experts in the field of quality control make it easier. In the operation, the officer only evaluates $\mathrm{X} 1, \mathrm{X} 2$, $\mathrm{Y} 1, \mathrm{Y} 2 \Delta \mathrm{X}+\Delta \mathrm{Y}$ then center the FFD according to the test carried out then just press the result button and the result of the difference in the $\mathrm{x}$-ray beam will appear Pass or Fail. This software was developed to be applied on smartphones so that it has the advantage of being simpler and more practical to carry, making it easier for users to mobilize. The weakness of the software is the possibility of force close when the video recording file is more than 5 seconds long.

\section{Conclusion}

The creation of the Dev-X collimator test tool hardware with intensifying screen, clear acrylic, transparent stickers with measurement scale, black foam, B-Pro action camera, and tripod and the creation of the Dev$\mathrm{X}$ collimator test tool software on an android smartphone to perform image processing
(Image Grabbing, Image Transformation) and display the results of the $\mathrm{x}$-ray beam calculation automatically.

From the results of research and discussion, it can be suggested that:

1. There needs to be further research on the material quality of the Dev-X hardware.

2. There needs to be a development of the software to minimize force close.

3. Need for further research and testing with more varied samples and test variations

\section{Reference}

1. Gatot M. Wibowo R, Sulistiyadi AH, Jurusan. Implementation of Compliance Testing Program on a Direct Digital Radiography ( DDR ) X-Ray System at the Radiography and Imaging Laboratory of the Health Polytechnic Ministry of Health Semarang Penerapan Program Uji Kesesuaian Pada Peralatan Sinar-X Direc. 2014;10(2):792-800.

2. Keputusan Mentri Kesehatan KMK no 1250. Tentang Pedoman Kendali Mutu (Quality Control) Peralatan Radiodiagnostik. 2009.

3. BAPETEN. Uji Kesesuaian Pesawat Sinar-X Radiologi Diagnostik Dan Intervensionali.; 2018.

4. Technology R. Collimator and Beam Alignment QC Tools Gammex Model 161B. 2015;31(0).

5. Meechai T, Chousangsuntorn K, Owasirikul W, Mongkolsuk M, Iampa W. Comparison of testing of collimator and beam alignment, focal spot size with slit camera, and tube current consistency using computed radiography and conventional screen - film systems. 2019;(March):160-169. doi:10.1002/acm2.12600

6. RTI. Nova An X-ray/Light Field/Digital Image Alignment tool. J Chem Inf Model. 2013;53(9):1689-1699. doi:10.1017/CBO9781107415324.004 